\title{
Formulation, characterization and wound-healing potential of emulgel and in-situ gel containing root extract of Saussurea lappa Clarke (Asteraceae)
}

\author{
Aitazaz Ahsan, Ghulam A Miana, Humaira Naureen*, Masood U Rehman, Kamil \\ Anum, Imran Malik \\ Riphah Institute of Pharmaceutical Sciences, Riphah International University, Islamabad, Pakistan
}

*For correspondence: Email: humaira.naureen@riphah.edu.pk; Tel: +92-304-5162135

Sent for review: 30 August 2019

Revised accepted: 14 December 2019

\begin{abstract}
Purpose: To investigate the wound-healing potential of herbal formulations (emulgels and in situ gels) containing Saussurea lappa root extract (SLRE) via excision wound induction in albino rats.

Methods: Preliminary phytochemical analysis of the methanol extract of roots of Saussurea lappa (SLRE) was performed using standard procedures. In vitro anti-inflammatory assay of SLRE was conducted using heat-induced hemolysis method at a concentration of $100 \mu \mathrm{g} / \mathrm{mL}$. Acute toxicity of $S L R E$ was also evaluated in mice at a single dose of $1000 \mathrm{mg} / \mathrm{kg}$ for $24 \mathrm{~h}$. Emulgels and in situ gels were prepared using different concentrations of SLRE and assessed for their organoleptic and physical properties. In vitro drug release studies of the prepared formulations were carried out by Franz diffusion cell and the data fitted into various pharmacokinetic models. Wound healing was assessed using excision wound induction $\left(380 \mathrm{~mm}^{2}\right)$ on dorsal surface of male albino rats. Each formulation (F4, F5, F6, G1, G2 and G3) and pyodine gel (standard) were applied topically (0.5 g) for 20 days. Wound contraction was measured every fourth day.

Results: SLRE showed $42.8 \%$ inhibition in heat-induced hemolysis on erythrocyte membrane model, compared to aspirin (positive control). Moreover, SLRE did not cause mortality in mice at the given doses. All the formulations were stable after one month stability check at $40{ }^{\circ} \mathrm{C}$ for emulgels and at 25 ${ }^{\circ} \mathrm{C}$ for in situ gels. All the formulations followed first order drug release pattern. In situ gel (G3) exhibited better wound healing (100 \pm 0.0028$)$ than emulgel (F6, $99 \pm 0.004)$ containing $5 \mathrm{~g}$ extract and standard pyodine gel $(91 \pm 0.014, p<0.05)$.

Conclusion: The results indicate that in situ gel of SLRE exhibits significant wound healing in rats. Thus, the findings present a strategy for the formulation of gel products with better wound healing potentials.
\end{abstract}

Keywords: Saussurea lappa, Wound healing, Emulgel, In situ gel, Herbal formulation

This is an Open Access article that uses a fund-ing model which does not charge readers or their institutions for access and distributed under the terms of the Creative Commons Attribution License (http://creativecommons.org/licenses/by/4.0) and the Budapest Open Access Initiative (http://www.budapestopenaccessinitiative.org/read), which permit unrestricted use, distribution, and reproduction in any medium, provided the original work is properly credited.

Tropical Journal of Pharmaceutical Research is indexed by Science Citation Index (SciSearch), Scopus, International Pharmaceutical Abstract, Chemical Abstracts, Embase, Index Copernicus, EBSCO, African Index Medicus, JournalSeek, Journal Citation Reports/Science Edition, Directory of Open Access Journals (DOAJ), African Journal Online, Bioline International, Open-J-Gate and Pharmacy Abstracts

\section{INTRODUCTION}

Natural products are very diverse and almost 35,000 - 70,000 plants species have been screened till date for their pharmacological activities. Ethno-pharmacological use of crude drugs provided a major clue in drug discovery. Data suggested that more than $50 \%$ of medicines used during last 30 years were of 
natural origin [1]. Saussurea lappa Clarke belonging to Asteraceae family of flowering plants and commonly known as costus or kuth occurs in South East Asia and Pakistan. This plant is traditionally used as home remedy in wide range of ailments including myalgia, cancer, rheumatoid arthritis and wound healing, etc [2].

Healing of wound is an important physiological mechanism that involves hemostasis, inflammation, proliferation and remodeling with highly programmed phases. These phases are necessary for proper wound healing in a proper sequence and time frame [3]. Saussurea lappa roots contain variety of phytochemicals like sesquiterpene-lactones that have antiinflammatory and wound healing potential. Alnahdi et al. reported that gastric ulcers were inhibited by costunolide and saussureamines which were obtained from roots of Saussurea lappa [4]. Cyanopicrin is an another phytochemical found in roots of Saussurea lappa that has been reported as potent immunosuppressive agent [5].

Topical drug delivery system is a conventional drug delivery system in which drugs are easily delivered through skin and include ointments, creams etc. But topical dosage forms have some drawbacks like low bioavailability and poor retention [6]. Emulgels and in situ gels are emerging techniques for topical drug delivery system. Emulgels provide dual control release in the form of emulsion as well as gel [7] whereas in situ gelling system involves use of polymers that have phase transition from solution to gel upon alterations in physico-chemical properties of drug [8]. Herbal formulations have become popular due to their natural origin and are used in variety of health ailments like liver problems, diabetes and heart problems [9]. Therefore, main purpose of the present study is to develop herbal formulations of Saussurea lappa root extract and evaluate their wound healing potential.

\section{EXPERIMENTAL}

\section{Chemicals}

Chloroform, n-hexane, ethyl acetate and methanol were used as solvents for extraction. HPMC k15M, polaxomer P407, carbopol 934, polyvinyl alcohol and benzyl alcohol were used as polymers for formulations development. Aspirin was obtained as a gift from Medizan Laboratories Pvt. Ltd. Islamabad and used as standard for in vitro anti-inflammatory assay. Pyodine gel was purchased from local Pharmacy and used as positive control for wound healing activity. All the chemicals were of highest grade purity.

\section{Plant collection and extraction}

The roots of Saussurea lappa were collected from the wild cultures growing in and around Swat valley, Pakistan in April 2018. The plant had been identified by Dr. Mushtaq Ahmed, a taxonomist at the Department of Plant Sciences, Quaid-i-Azam University, Islamabad, Pakistan and provided voucher specimen number as 025120. Roots were shade dried and then grounded coarsely. Four extracts were prepared using methanol $(\mathrm{MeOH})$, ethyl acetate (EtOAc), chloroform (CF) and n-hexane through soxhelt extractor which were concentrated under reduced pressure at $40-50{ }^{\circ} \mathrm{C}$ using rotary evaporator.

\section{Thin layer chromatography and preliminary phytochemical screening}

Analytical TLC was performed for the detection of sesquiterpene lactones in the crude extracts. The plates (TLC Silicagel; Merck KGaA, Darmstadt, Germany) were spotted with $5-10$ $\mu \mathrm{g}$ of each extract and placed in glass chamber containing chloroform and methanol (9:1). After development, all the plates were dried and exposed to iodine vapors followed by heating. After 20 minutes, the plates were observed. Furthermore, preliminary phytochemical analysis of the extracts was performed to detect the presence of flavonoids, terpenoids, carbohydrates, alkaloids, proteins, tannins, saponins, phenolic compounds and glycosides using standard procedures [10].

\section{In vitro anti-inflammatory assessment of crude extract}

The blood sample $(5 \mathrm{ml})$ was withdrawn from a healthy human volunteer and centrifuged for 10 $\mathrm{min}$ at $3000 \mathrm{rpm}$. After washing the blood cells with normal saline thrice, finally $10 \% \mathrm{v} / \mathrm{v}$ suspension of the RBCs was prepared by adding normal saline. For heat induced hemolytic assay $2 \mathrm{ml}$ of mixture containing $1 \mathrm{~mL}$ of $10 \%$ RBCs suspension and $1 \mathrm{~mL}$ test sample $(100 \mu \mathrm{g} / \mathrm{mL}$ of crude extract) were mixed. For positive control aspirin while for negative control normal saline was used. The mixture was incubated in a water bath at $56{ }^{\circ} \mathrm{C}$ for $30 \mathrm{~min}$ and then centrifuged again at $2500 \mathrm{rpm}$ for $5 \mathrm{~min}$. Absorbance of the supernatants was recorded at $560 \mathrm{~nm}$ [11]. The percentage inhibition $(\mathrm{H})$ of hemolysis was calculated as in Eq 1.

$H(\%)=\{(\mathrm{Ac}-\mathrm{As}) / \mathrm{Ac}\} 100 \ldots \ldots \ldots(1)$ 
where $A_{c}$ and $A_{s}$ are the absorbance of control and test samples respectively.

\section{Animals}

Male Balb-C mice $(20-30 \mathrm{~g})$ and Albino rats $(180-220 \mathrm{~g})$ were housed at the Animal House of Riphah Institute of Pharmaceutical Sciences Islamabad, at $25 \pm 2{ }^{\circ} \mathrm{C}$. All the experiments complied to the rules of Institute of Laboratory Animals Resources, Commission on Life Science University, National Research Council, 1996 [12] and approved by Research and Ethics Committee (REC) of Riphah Institute of Pharmaceutical Sciences Islamabad (approval ref no. REC/RIPS/2019/19).

\section{Acute toxicity study}

Acute oral toxicity assay was performed on twelve male Balb-C mice $(20-30 \mathrm{~g})$ which were divided into two groups $(n=6)$. Experimental group was orally given $1000 \mathrm{mg} / \mathrm{kg}$ dose of SLRE dissolved in normal saline while mice in control group were administered normal saline $(10 \mathrm{~mL} / \mathrm{kg})$. Any sign of toxicity or death was observed during $24 \mathrm{~h}$ [13].

\section{Formulation development}

\section{Emulgels}

Six formulations of emulgels (F1-F6) containing SLRE (0.5-5 g) were prepared by separately making oil phase (liquid paraffin and span 80 ) and aqueous phase (distilled water and tween 80) Oil phase was added in aqueous phase and carbopol 940 dissolved in distilled water was added. After that methanolic extract, PEG 4000, methyl paraben and eucalyptus oil were incorporated in this mixture and blended thoroughly to make final formulation [14]. Composition of emulgels is shown in Table 1.

\section{In situ gels}

Three formulations of in situ gels (G1-G3) with SLRE (3-5 g) were prepared by mixing aqueous preparation of $15 \%$ polaxomer $407,2 \%$ carbopol 940, $15 \%$ hydroxy propyl methyl cellulose (k15) and $1 \%$ poly vinyl alcohol. Lyophilized extract was added in formulations and mixed thoroughly $[15,16]$. Composition of in situ gels is shown in Table 2.

\section{Characterization of formulations}

Emulgels were observed for appearance, grittiness and phase separation. Phase separation was checked through centrifugation of emulgels at $3000 \mathrm{rpm}$ for $10 \mathrm{~min}$. Spreadability was determined by placing $350 \mathrm{mg}$ of formulation on a glass slide while second slide was placed from the $5 \mathrm{~cm}$ over the first slide and diameter of circle was measured. A pH meter was used to determine $\mathrm{pH}$ while Brookfield viscometer (spindle 61 at $100 \mathrm{rpm}$ ) was used to measure viscosity. Swelling index was noted by placing 1 $\mathrm{g}$ of formulation on aluminum foil in which pores were created and then placed in $10 \mathrm{~mL}$ of $0.1 \mathrm{~N}$ $\mathrm{NaOH}$. Samples were collected and dried for 30 min. After drying samples were reweighed and \% swelling index (SW) was calculated as shown in Eq 2.

Table 1: Composition of emulgel formulations containing SLRE

\begin{tabular}{lccccccccc}
\hline Formulation & $\begin{array}{c}\text { SLRE } \\
(\mathbf{g})\end{array}$ & $\begin{array}{c}\text { Carbopol } \\
\mathbf{9 4 0} \\
(\mathbf{g})\end{array}$ & $\begin{array}{c}\text { Span } \\
\mathbf{8 0} \\
(\mathbf{m L})\end{array}$ & $\begin{array}{c}\text { Tween } \\
\mathbf{8 0}\end{array}$ & $\begin{array}{c}\text { Liquid } \\
\text { Paraffin } \\
(\mathbf{m L})\end{array}$ & $\begin{array}{c}\text { Methyl } \\
\text { paraben } \\
(\mathbf{g})\end{array}$ & $\begin{array}{c}\text { Eucalyptus } \\
\text { oil } \\
(\mathbf{m L})\end{array}$ & $\begin{array}{c}\text { PEG } \\
\mathbf{4} \mathbf{4 0 0 0} \\
(\mathbf{m L})\end{array}$ & $\begin{array}{c}\text { Water } \\
(\mathbf{m L})\end{array}$ \\
\hline F1 & & 3 & 1.8 & 2 & 10 & 0.1 & 0.1 & 10 & 10 \\
F2 & 1 & 3 & 1.8 & 2 & 10 & 0.1 & 0.1 & 10 & 10 \\
F3 & 2 & 3 & 1.8 & 2 & 10 & 0.1 & 0.1 & 10 & 10 \\
F4 & 3 & 3 & 1.8 & 2 & 10 & 0.1 & 0.1 & 10 & 10 \\
F5 & 4 & 3 & 1.8 & 2 & 10 & 0.1 & 0.1 & 10 & 10 \\
F6 & 5 & 3 & 1.8 & 2 & 10 & 0.1 & 0.1 & 10 & 10 \\
\hline
\end{tabular}

Table 2: Composition of in situ gel formulations containing SLRE

\begin{tabular}{|c|c|c|c|c|c|c|}
\hline Formulation & 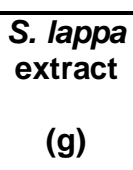 & $\begin{array}{c}\text { Carbopol } \\
940 \\
2 \% \\
(\mathrm{~g})\end{array}$ & $\begin{array}{c}\text { HPMC k } \\
15 \\
15 \% \\
(g)\end{array}$ & $\begin{array}{c}\text { Poly vinyl } \\
\text { alcohol } \\
1 \% \\
(\mathrm{~g})\end{array}$ & $\begin{array}{c}\text { Polaxomer } \\
407 \\
15 \% \\
\text { (g) }\end{array}$ & $\begin{array}{c}\text { Distilled } \\
\text { water } \\
(\mathrm{mL})\end{array}$ \\
\hline $\begin{array}{l}\text { G1 } \\
\text { G2 } \\
\text { G3 }\end{array}$ & $\begin{array}{l}3 \\
4 \\
5\end{array}$ & $\begin{array}{l}1 \\
1 \\
1\end{array}$ & $\begin{array}{l}7.5 \\
7.5 \\
7.5\end{array}$ & $\begin{array}{l}0.5 \\
0.5 \\
0.5\end{array}$ & $\begin{array}{l}7.5 \\
7.5 \\
7.5\end{array}$ & $\begin{array}{l}200 \\
200 \\
200\end{array}$ \\
\hline
\end{tabular}


$\mathrm{SW}=\left\{\left(\mathrm{W}_{\mathrm{t}}-\mathrm{W}_{\mathrm{o}}\right) / \mathrm{W}_{\mathrm{o}}\right\} 100$

While $W_{t}$ is the weight after time $t$ and $W_{0}$ is the weight at time zero respectively.

In situ gels were observed for appearance while $\mathrm{pH}$, spreadability and viscosity were determined as mentioned earlier for emulgels [17]. Moreover, Emulgels were stored at $40{ }^{\circ} \mathrm{C}$ whereas in situ gels were stored at $25{ }^{\circ} \mathrm{C}$ and different parameters like $\mathrm{pH}$, viscosity were determined every week for one month according to $\mathrm{ICH}$ guidelines [18].

\section{In vitro drug release studies}

Modified Franz diffusion cell was used for in vitro drug release studies using $0.22 \mu \mathrm{m}$ dialysis membranes. Donor compartment was filled with emulgels and in situ gels whereas recipient compartment contained phosphate buffer $(\mathrm{pH}$ 6.0). Magnetic bar with teflon coating was put in recipient chamber and rotated at $50 \mathrm{rpm}$. Temperature of Franz diffusion cell was kept at $37^{\circ} \mathrm{C}$ by circulating heated water in the outer jacket. Samples were removed at 0, 1, 2, 3, 4, 5, 6,7 and $8 \mathrm{~h}$ while absorbance was determined at $332 \mathrm{~nm}$ using UV-VIS spectrophotometer as shown in Eq 3 after dilution with phosphate buffer [14].

$A=\left\{\left(A_{s} / A_{c}\right)\right\} 100$

Where $A_{c}$ and $A_{s}$ are the absorbance of control and test sample respectively.

\section{Evaluation of kinetic release mechanism}

Data obtained from in vitro drug release study was fitted into various kinetic models like first order model, Higuchi model and Hixson Crowell model for the evaluation of kinetic release [19].

\section{First order model}

It establishes the relationship between percentage drug release and time. Integration and rearrangement is shown in Eq 4.

$\log C_{t}=\log C_{0}+K t / 2.303$

where $\mathrm{K}$ is the first order rate equation, $\mathrm{C}_{0}$ is the initial concentration of the drug, $C_{t}$ is the remaining drug at any particular time, and $t$ is the time in hours.

\section{Higuchi model}

It is most prominent pharmacokinetic model that involves drug dissolution and diffusion which depends on drug concentration. Simplified form of Highuchi equation is shown in Eq 5.

$Q=K_{H} \times t^{1 / 2}$

where $Q$ is the Cumulative amount of drug released at time $t, K_{H}$ is the Higuchi release rate constant and $t^{1 / 2}$ is the square root of time.

\section{Hixson-Crowell model}

It mainly describes the drug release from a polymeric system that involves changes in surface area and diameter of drug molecules. Simplified relationship between drug release and time is given in Eq 6 .

$\mathrm{W}_{0}^{1 / 3}-\mathrm{W}_{\mathrm{t}}^{1 / 3}=\mathrm{K}_{\mathrm{Hc}} \mathrm{t}$.

where $W_{0}{ }^{1 / 3}$ is the cube root of initial amount of drug present in the matrix, $W_{t}^{1 / 3}$ is the cube root of remaining amount of drug in matrix at time, $\mathrm{K}_{\mathrm{Hc}}$ is the release rate constant and $t$ is the time.

\section{Wound healing study}

Male albino rats in nine $(I-I X)$ groups $(n=4)$ were used for the study. Ketamine $(25 \mathrm{mg} / \mathrm{kg})$ was used for anesthesia and the dorsal surface of each rat was shaved with sterile razor. Excision wound of $380 \mathrm{~mm}^{2}$ was induced in all rats. The wounds were kept open and treated as follows:

Groups I-VI were treated topically with $0.5 \mathrm{~g}$ of each formulation (F4, F5, F6, G1, G2 and G3) while group VII served as positive control group administered with topical pyodine gel (PG).

Group VIII was treated with crude extract SLRE (200 mg/10mL) while Group IX was untreated group and served as negative control group.

Wound size was measured after every four days for a period of twenty days and percentage wound contraction (WC) was determined as mentioned in Eq 7 [20].

$\mathrm{WC}(\%)=\left\{\left(\mathrm{W}_{0}-\mathrm{W}_{\mathrm{t}}\right) / \mathrm{W}_{0}\right\} 100 \ldots \ldots \ldots(7)$

where $W_{0}$ is the initial wound size and $W_{t}$ is the wound size on specific day.

\section{Statistical analysis}

Values were presented as mean \pm standard error of mean (SEM) and were analyzed by one-way analysis of variance (ANOVA) in Microsoft Excel $^{\Theta}$. Differences in values were considered statistically significant at $P<0.05$. 


\section{RESULTS}

Thin layer chromatography and preliminary phytochemical prrofile

Brownish spots of sesquiterpene lactones were detected on the TLC plate containing methanolic extract of Saussurea lappa roots (SLRE) whereas no spots were observed in plates containing EtoAc, CF and n-hexane extracts. Preliminary phytochemical screening of SLRE showed positive results for alkaloids, glycosides, flavanoids, terpenoids, saponins, tannins, phenols and carbohydrates but negative results for proteins. These results are presented in Table 3.

Table 3: Preliminary phytochemical screening of $S$. lappa root extract

\begin{tabular}{llc}
\hline Phytochemical & Indication & Result \\
\hline Alkaloids & $\begin{array}{l}\text { Reddish } \\
\text { brown } \\
\text { pecipitates }\end{array}$ & + \\
Glycosides & $\begin{array}{l}\text { Brown color } \\
\text { Staple froth }\end{array}$ & + \\
& $\begin{array}{l}\text { for 10 } \\
\text { minutes }\end{array}$ & ++ \\
Phenols and tannins & $\begin{array}{l}\text { Blue green } \\
\text { color }\end{array}$ & ++ \\
Proteins & No change & - \\
Carbohydrates & Brick red & + \\
Flavanoids & color & \\
& Intense & ++ \\
Terpenoids & yellow color & \\
\hline (++)StronglyPresent, $(+)$ Weakly Present, (-) Absent
\end{tabular}

\section{In vitro anti-inflammatory activity}

SLRE exhibited $42.8 \%$ inhibition in heat induced hemolysis on erythrocyte membrane model compared to aspirin $(51 \%)$ at a concentration of $100 \mu \mathrm{g} / \mathrm{mL}$.

\section{Acute toxicity}

Neither mortality nor any sign of toxicity at tested dose $(1000 \mathrm{mg} / \mathrm{kg})$ was observed after $24 \mathrm{hr}$.

\section{Characteristics of the formulations}

Emulgel formulations (F1-F6) were yellowish brown in color while in situ gels (G1-G3) were brown in color. No grittiness and phase separation (done by centrifugation) was observed in any formulation. $\mathrm{pH}$ and viscosity of emulgels and in situ gels did not change. Results for characterization of emulgels are shown in Table 4 while in situ gel formulations are presented in Table 5. Furthermore, F6 and G3 were placed at accelerated conditions to check their stability because profound wound healing effect was observed by these two formulations. Stability studies for emulgels were performed at $40{ }^{\circ} \mathrm{C}$ whereas in situ gels were evaluated by storing them at $25{ }^{\circ} \mathrm{C}$ for 4 weeks as shown in Table 6 and 7 respectively. No change in color was seen and phase separation was also not observed throughout the study period.

\section{Drug release kinetics}

Various mathematical models were designed to correlate drug permeation profile with drug

Table 4: Some characteristics of emulgels

\begin{tabular}{lcccc}
\hline Formulation & $\mathbf{p H}$ & $\begin{array}{c}\text { Viscosity } \\
\text { (cps) }\end{array}$ & $\begin{array}{c}\text { Swelling index } \\
\text { (\%) }\end{array}$ & $\begin{array}{c}\text { Spreadability } \\
\text { (cm/s) }\end{array}$ \\
\hline F1 & & & \\
F2 & $6.83 \pm 0.021$ & $1567.8 \pm 0.031$ & $56.2 \pm 0.032$ & $18 \pm 0.041$ \\
F3 & $6.92 \pm 0.028$ & $1575.0 \pm 0.042$ & $69.3 \pm 0.021$ & $20 \pm 0.045$ \\
F4 & $6.35 \pm 0.027$ & $1589.0 \pm 0.032$ & $88.5 \pm 0.042$ & $16 \pm 0.039$ \\
F5 & $6.79 \pm 0.031$ & $1596.0 \pm 0.021$ & $85.4 \pm 0.041$ & $16 \pm 0.023$ \\
F6 & $7.12 \pm 0.025$ & $1612.3 \pm 0.026$ & $89.6 \pm 0.038$ & $18 \pm 0.039$ \\
\hline
\end{tabular}

Values are mean \pm SEM $(n=4) P<0.05$

Table 5: Characteristics of in-situ gels

\begin{tabular}{lccc}
\hline Formulation & $\mathbf{p H}$ & $\begin{array}{c}\text { Viscosity } \\
\text { (cps) }\end{array}$ & $\begin{array}{c}\text { Spreadability } \\
\text { (cm/s) }\end{array}$ \\
\hline G1 & $6.73 \pm 0.014$ & $1665.0 \pm 0.021$ & $17 \pm 0.012$ \\
G2 & $6.62 \pm 0.015$ & $1682.5 \pm 0.034$ & $19 \pm 0.017$ \\
G3 & $6.89 \pm 0.021$ & $1696.0 \pm 0.023$ & $16 \pm 0.018$ \\
\hline Values are mean + SEM $(n=4, p<0.05$ & &
\end{tabular}


Table 6: Stability of emulgel (F6) at $40^{\circ} \mathrm{C}$

\begin{tabular}{lcc}
\hline Time (week) & \multicolumn{2}{c}{ Parameter } \\
\hline & $\boldsymbol{p H}$ & Viscosity $(\boldsymbol{c p s})$ \\
\cline { 2 - 3 } $\mathbf{0}$ & $6.89 \pm 0.031$ & $1619.7 \pm 0.048$ \\
$\mathbf{1}$ & $6.88 \pm 0.021$ & $1600.7 \pm 0.054$ \\
$\mathbf{2}$ & $6.88 \pm 0.033$ & $1584.1 \pm 0.056$ \\
$\mathbf{3}$ & $6.89 \pm 0.021$ & $1578.2 \pm 0.096$ \\
$\mathbf{4}$ & $6.89 \pm 0.034$ & $1570.8 \pm 0.052$ \\
\hline \multicolumn{2}{l}{ Values are mean \pm SEM P $<0.05$} \\
\end{tabular}

Table 7: Stability of in situ gel (G3) at $25^{\circ} \mathrm{C}$

\begin{tabular}{lcc}
\hline Time (week) & \multicolumn{2}{c}{ Parameter } \\
\hline & $\boldsymbol{p H}$ & Viscosity $(\boldsymbol{c p s})$ \\
$\mathbf{0}$ & $6.89 \pm 0.051$ & $1696.0 \pm 0.068$ \\
$\mathbf{1}$ & $6.89 \pm 0.073$ & $1698.9 \pm 0.074$ \\
$\mathbf{2}$ & $6.89 \pm 0.081$ & $1698.5 \pm 0.059$ \\
$\mathbf{3}$ & $6.90 \pm 0.093$ & $1699.5 \pm 0.088$ \\
$\mathbf{4}$ & $6.90 \pm 0.096$ & $1699.6 \pm 0.093$ \\
\hline \multicolumn{2}{l}{ Values are mean \pm SEM $(p<0.05)$}
\end{tabular}

release kinetics [19]. The findings showed that all formulations released drug constantly over the period of time and better release rates were observed with in situ gels when compared to emulgels. All formulations followed first order release pattern. Values of $r^{2}$ and $r^{3}$ are presented in Tables 8, 9 and 10.

Table 8: First order release pattern of emulgel (F6) and in-situ gel (G3)

\begin{tabular}{lcc}
\hline Time (h) & \multicolumn{2}{c}{ Log cumulative percent release $\left(\mathbf{r}^{2}\right)$} \\
\cline { 2 - 3 } $\mathbf{1}$ & Emulgel & In situ gel \\
$\mathbf{2}$ & 2.63 & 2.19 \\
$\mathbf{3}$ & 1.66 & 1.58 \\
$\mathbf{4}$ & 1.20 & 1.26 \\
$\mathbf{5}$ & 0.94 & 1.01 \\
$\mathbf{6}$ & 0.83 & 0.84 \\
$\mathbf{7}$ & 0.72 & 0.72 \\
$\mathbf{8}$ & 0.62 & 0.63 \\
\hline
\end{tabular}

Table 9: Higuchi model for release pattern of emulgel (F6) and in-situ gel (G3)

\begin{tabular}{lcc}
\hline $\begin{array}{l}\text { Square root of } \\
\text { time }\left(\mathbf{t}^{\mathbf{1 / 2}}\right)\end{array}$ & \multicolumn{2}{c}{ Cumulative percent release } \\
$\left(\mathbf{r}^{2}\right)$
\end{tabular}

\section{Wound healing activity}

All the emulgels (F1-F6) and in situ gels (G1-G3) were tested for wound healing potential but emulgel formulations F1, F2 and F3 showed negligible wound healing effect. So we did not use these formulations further. The emulgels (F4-F6) and in situ gel (G1-G3) demonstrated substantial contraction of wounds and improved epithelialization in rats as compared to control groups. Results are shown in Table 11.

Table 10: Hixson-Crowell model for release pattern of emulgel (F6) and in-situ gel (G3)

\begin{tabular}{lcc}
\hline Time $(\mathbf{h})$ & \multicolumn{2}{c}{ Cube root of release $\left(\mathbf{r}^{3}\right)$} \\
\cline { 3 - 3 } $\mathbf{1}$ & Emulgels & In situ gels \\
$\mathbf{n}$ & -2.46 & -2.19 \\
$\mathbf{3}$ & -0.03 & -0.38 \\
$\mathbf{4}$ & -0.09 & -0.26 \\
$\mathbf{5}$ & -0.04 & -0.09 \\
$\mathbf{6}$ & -0.09 & -0.03 \\
$\mathbf{7}$ & -0.04 & -0.02 \\
$\mathbf{8}$ & -0.02 & -0.01 \\
\hline
\end{tabular}

\section{DISCUSSION}

This study demonstrated the wound healing potential of herbal formulations (emulgels and in situ gels) of SLRE.

Emulgels and In-situ gelling system are the recent formulations in novel drug delivery systems that provide controlled drug release $[6,7]$. Saussurea lappa possess important pharmacological properties such as anti-ulcer, wound healing, anti-inflammatory and anticonvulsant, etc [21].

The methanolic extract of Saussurea lappa was shown to contain alkaloids, glycosides, flavonoids, terpenoids, carbohydrates, saponins and taninns [10]. Sesquiterpene lactones were also detected in methanolic SLRE through TLC therefore, formulations were developed using methanolic extract. Acute toxicity study of SLRE indicates lower toxicity profile of Saussurea lappa. In vitro anti-inflammatory assay showed that SLRE could be beneficial in reducing inflammation because it had inhibited heat induced hemolysis and shown comparable effect with aspirin in this study. As NSAIDs cause gastric ulcers over long term use while the herbal extracts are safer than these drugs. Herbs are always important in maintaining normal health due to their low toxicity profile and the use of herbal formulations is also becoming popular because of lesser side effects [9].

Emulgels (F1-F6) and in situ gels (G1-G3) were evaluated by organoleptic and physical parameters like color, grittiness, phase separation, spreadability, $\mathrm{pH}$, swelling index and viscosity. No change in color of formulations was 
Table 11: Wound healing assessment of formulations in experimental rats

\begin{tabular}{lccccc}
\hline Formulation & \multicolumn{5}{c}{ Wound contraction (\%) } \\
\cline { 2 - 6 } & Day 4 & Day 8 & Day 12 & Day 16 & Day 20 \\
\hline F4 & $10 \pm 0.014$ & $35 \pm 0.025$ & $50 \pm 0.030$ & $67 \pm 0.031$ & $84 \pm 0.036$ \\
F5 & $13 \pm 0.022$ & $37 \pm 0.400$ & $53 \pm 0.018$ & $72 \pm 0.016$ & $88 \pm 0.027$ \\
F6 & $20 \pm 0.017$ & $43 \pm 0.025$ & $62 \pm 0.026$ & $79 \pm 0.024$ & $99 \pm 0.004$ \\
G1 & $21 \pm 0.010$ & $46 \pm 0.024$ & $72 \pm 0.025$ & $87 \pm 0.020$ & $96 \pm 0.008$ \\
G2 & $28 \pm 0.064$ & $50 \pm 0.025$ & $78 \pm 0.021$ & $92 \pm 0.013$ & $97 \pm 0.008$ \\
G3 & $31 \pm 0.009$ & $55 \pm 0.020$ & $84 \pm 0.019$ & $99 \pm 0.002$ & $100 \pm 0.002$ \\
PG & $17 \pm 0.009$ & $41 \pm 0.029$ & $70 \pm 0.020$ & $84 \pm 0.023$ & $91 \pm 0.014$ \\
SLRE & $22 \pm 0.013$ & $43 \pm 0.027$ & $75 \pm 0.026$ & $86 \pm 0.010$ & $94 \pm 0.019$ \\
Untreated group & $9 \pm 0.011$ & $26 \pm 0.017$ & $45 \pm 0.006$ & $65 \pm 0.021$ & $77 \pm 0.016$ \\
\hline Values are mean \pm SEM $(\mathrm{n}=4, p<0.05)$ &
\end{tabular}

observed at the end of study indicating that formulations were stable at storage conditions. No grittiness felt in any formulation displaying that particle size of excipients is small and not increased with time. No phase separation on centrifugation in case of emulgels shows that formulations are stable. Viscosity of emulgel formulations decreased at high temperature because at high temperature surfactants in the emulgel can obtain energy from the heat and interfacial film between dispersed phase and dispersion medium become reduced and make the formulations less viscous.

While viscosity of in situ gels was increased because in situ gels undergo gelation on high temperature [14-15], the $\mathrm{pH}$ of the formulations did not change noticeably however slight variation was noticed in $\mathrm{pH}$ showing that formulations are stable and can be used topically for wound healing purposes without irritating the outer skin layers. Spreadability of all formulations was in an acceptable range revealing that formulations are easy to spread without any difficulty by little shear [17]. In vitro drug release results showed that formulations (F6 and G3) followed first order model for drug release which indicates that drug release is dependent on the quantity of drug left as compared to Higuchi model in which release of drug is dependent on diffusion of drug from polymers and Hixson Crowell model that describes percentage of drug remaining in matrix verses time [19].

Wound healing effect of formulations (F1-F3) was negligible which may be due to very low concentration of extract used. Formulations F6 and G3 exhibited maximum wound healing effect. It means that wound healing effect was dose dependent and results revealed that wound healing activity was improved as the amount of extract in the formulations increased. So these two formulations (F6 and G3) were selected for stability testing and in vitro drug release study.
Results of wound healing activity of emulgels and in situ gels were statistically significant in comparison to positive (PG) and negative control group (untreated group) with $P<0.05$. When emulgels and in situ gels results were compared, it was observed that in situ gels were more effective in healing the wounds due to their better in vitro drug release as polaxomer 407 inhibit the effect of efflux pumps that cause drug to stay into the cells for a longer period of time than emulgels and these results were statistically significant [21].

Moreover, wound healing results for SLRE were also statistically significant when compared to $P G$ and untreated group $P<0.05$. The present study also indicated that in situ gel (G3) promoted better wound healing by increasing wound contraction and epithelialization. Emulgel containing SLRE also showed better wound healing as compared to pyodine gel may be due to the antioxidant rich compounds that are present in SLRE. Several studies have shown that Saussurea lappa is used in treatment of more than 43 diseases including wound healing [22]. Exact mechanism of wound healing shown by SLRE is still unknown therefore; further molecular studies are required to investigate the possible underlying mechanisms.

\section{CONCLUSION}

The findings of this study reveal that SLRE contains a variety of phytochemicals such as sesquiterpene lactones that are responsible for its in vitro and in vivo activities including inhibition of heat induced hemolysis and wound healing. In situ SLRE gel demonstrates higher wound healing properties than emulgel, SLRE and even pyodine gel. Further studies are required to determine its feasibility as an alternative herbal medicine for the management of wounds. 


\section{DECLARATIONS}

\section{Acknowledgement}

The authors are thankful to Higher Education Commission (HEC) of Pakistan for providing financial support under National Research Program for Universities (NRPU) Project \# 20686.

\section{Conflict of interest}

No conflict of interest is associated with this work.

\section{Contribution of authors}

The authors declare that this work was done by the authors named in this article and all liabilities pertaining to claims relating to the content of this article will be borne by them. Ghulam Abbas Miana and Masood ur Rehman designed the study and supervised the project. Aitazaz Ahsan conducted literature search, experimental work, data analysis and drafted the manuscript. Kamil Anum and Imran Malik helped in carrying out the experimental work. Humaira Naureen supervised the study and helped in drafting and reviewing the final manuscript. All authors reviewed and approved the final manuscript for publication.

\section{Open Access}

This is an Open Access article that uses a funding model which does not charge readers or their institutions for access and distributed under the terms of the Creative Commons Attribution License (http://creativecommons.org/licenses/by/ 4.0) and the Budapest Open Access Initiative (http://www.budapestopenaccessinitiative.org/rea d), which permit unrestricted use, distribution, and reproduction in any medium, provided the original work is properly credited.

\section{REFERENCES}

1. Newman DJ, Cragg GM. Natural products as sources of new drugs over the 30 years from 1981 to 2010. J Nat Prod 2012; 75: 311-335.

2. Chen YS, Yuan Q. Twenty-six new species of Saussurea (Asteraceae, Cardueae) from the Qinghai-Tibetan plateau and adjacent regions. Phytotaxa 2015; 213 . 159-2113.

3. Guo S, Di Pietro LA. Factors affecting wound healing. $J$ Dent Res 2010; 89: 219-229.

4. Alnahdi HS, Ayaz N, Elhalwagy ME. prophylactic effect of coostus saussurea lappa against liver inury induced by delmethrin intoxication. Int J Clin Exp Patho 2016; 9: 387-394.

5. Sutar N, Garai R, Roy S. Anti-ulcerogenic activity of Saussurea lappa root. Int J Pharm Life Sci 2011; 2: 516520.

6. Jotinder K, Jasmeen K, Sandhya J, Ghanshyam DG. Recent advances in topical drug delivery system. Pharma Res 2016; 6: 2231-2239.

7. Yadav SK, Mishra MK, Tiwari A, Shukla A. Emulgel: A new approach for enhanced topical drug delivery. Int $J$ Curr Pharm Sci 2016; 9: 15-19.

8. Harish NM, Prabhu P, Charyulu RN, Gulzar MA, Subrahmanyan EVS. Formulation and evaluation of in situ gels containing clotrimazole for oral candidiasis. Indian J Pharma Sci 2009; 71: 421-431.

9. Chanchal $D$, Swarnlata $S$. Novel approaches in herbal cosmetics. J Cosmet Dermatol 2008; 7: 89-95.

10. Yadav R, Munin A, Phytochemical analysis of some medicinal plants. J phytol 2011; 3: 10-14.

11. Ranasinghe $P 1$, Ranasinghe $P$, Abeysekera WP, Premakumara GA, Perera YS, Gurugama $P$, Gunatilake $S B$. In-vitro erythrocyte membrane stabilization properties of Carica papaya $L$. leaf extracts. Pharmacognosy Res 2012; 4: 196-200.

12. National Research Council. Guide for the Care and Use of Laboratory Animal. Washington; National Academy Press 1996.

13. Singh $T$, Sinha $N$, Singh A. Biochemical and histopathological effects on liver due to acute oral toxicity of aqueous leaf extract of Eclipta alba on female swiss albino mice. Ind $J$ of pharma 2013; 45: 61-65.

14. Sultana S, Swapna G, Swathi S, Jyothi G, Devi S. Formulation and evaluation of herbal emulgel of Lantana camara leaves extract for wound healing activity in diabetic rats. Indo American J Pharm Res 2016; 6: 6404-4617.

15. Kaul A, Hazari PP, Rawat $H$, Singh B, Kalawat TC, Sharma S, Babbar AK, Mishra AK. Preliminary evaluation of technetium-99m-labeled ceftriaxone: infection imaging agent for the clinical diagnosis of orthopedic infection. Int J Infect 2013; 17: 263-270.

16. Katakam M, Ravis WR, Banga AK. Controlled release of human growth hormone in rats following parenteral administration of poloxamer gels. J Controlled Release 1997; 49: 21-26.

17. Khunt DM, Mishra $A D$, Shah DR. Formulation design \& development of piroxicam emulgel. Int $\mathrm{J}$ PharmTech Res 2012; 4: 1332-1344.

18. Q1A (R2): stability testing of new drug substances and products. Proceedings of the International Conference on Harmonization (ICH, 03); 2003; Geneva, Switzerland.

19. Gouda R, Baishya H, Qing Z, Application of mathematical models in drug release kinetics of carbidopa and levodopa ER tablets. J Dev Drugs 2017; 6: 156-165

20. Jagtap NS, Khadabadi SS, Farooqui IA, Nalamwar VP, Sawarkar HA. Development and evaluation of herbal wound healing formulations. Int J Pharm Tech Res 2009; 1: 1104-1108.

Trop J Pharm Res, January 2020; 19(1): 8 
Ahsan et al

21. Devi DR, Sandhya P, Hari BV. Poloxamer: a novel functional molecule for drug delivery and gene therapy. J Pharma Sci Res 2013; 5: 159-168.
22. Zahra K, Tabassum S, Sabir S, Arshad M, Qureshi R, Amjad MS, Chaudhari SK. A review of therapeutic potential of Saussurea lappa-An endangered plant from Himalaya. Asian Pac J Trop Med 2014; 7: 60-69. 